\title{
Special Jssue \\ The Cecil H. and Yda M. Green Institute of Geophysics and Planetary Physics (IGPP)
}

\author{
By the IGPP Directors: \\ Walter Munk 1962-1982 \\ Freeman Gilbert 1976-1988 \\ John Orcutt
}

\author{
Mark Zumberge 1990- \\ Robert Parker 2002-
}

We are all still alive! For 44 out of 100 years of its existence, Scripps has given us a unique base for building the La Jolla (LJ) branch of IGPP. We have enjoyed considerable freedom and authority in setting the course. We come from diverse backgrounds, with diverse interests, but there have been some common threads.

- Each of us managed to continue our personal research during, and following, our service as IGPP director. We believe our colleagues considered us to be part of the research effort instead of an administrative entity.

- IGPP is a research institute, not a teaching department, yet this distinction has never been a major issue. We have worked hard to minimize any class distinction between graduate students, postdocs, research staff, and faculty. Positions now occupied worldwide by our former students are a key indicator of our performance.

- Keeping pace with the computer revolution has been a central theme starting in 1963 with eighthole paper tape recordings of the antipodal propagation of ocean swell and culminating with today's Virtual Seismic Network. Digitization of seismometers, on land and the seafloor, has played a vital role in improving our understanding of geologic processes.

- We have taken an encompassing view of Earth, emphasizing the similarities, rather than the distinctions, of fluid and solid provinces. This symbiosis shows up in different ways including the renowned course in continuum mechanics, the transition of a seafloor tide gauge to a bottom seismometer, and the solution of joint fluid-solid interaction problems. A number of distinguished "fluid" geophysicists who were in residence at IGPP (though not formally on the IGPP faculty) are an important part of our story. Unfortunately, increasing specialization at Scripps has drawn away some of our colleagues in the fluid earth field.

- One of the most challenging problems has been the mix between individual scholarship and the teamwork required to collect data on a global scale. The pendulum has swung back and forth. Curiously, it was the work and interest of the "scholars" that initiated the most notable team efforts.

- We have made a concerted effort to provide an attractive home for the IGPP family. The directors and their wives participated to an unusual (perhaps unique) degree in the selection of architects and the subsequent planning, design, and construction of both IGPP laboratories in the 1960s and 1990s.

What follows are first-person recollections of what happened (or what we think we remember happened) during our tenure as directors. This is by no means a history of the institute. There is little coherence, and no attempt at completeness. We ask the forgiveness of our many partners whose contributions are not an explicit part of this sketch.

\section{Walter Munk Writes}

After 15 years at Scripps, I spent 1956 on sabbatical leave in England. Sir Edward (Teddy) Bullard had just returned to Madingley Rise (now the Bullard Laboratory) at Cambridge University, after some years as director of the National Physical Laboratory. His influence was to prove crucial to the development of IGPP/LJ (Figure 1).

I returned to La Jolla full of enthusiasm for the scholarly atmosphere at Madingley Rise. In England, I had worked on an early draft of The Rotation of the Earth, which involved most of the diverse geophysical disciplines. ${ }^{2}$ I was seriously tempted by offers from the Massachusetts Institute of Technology (MIT) and 


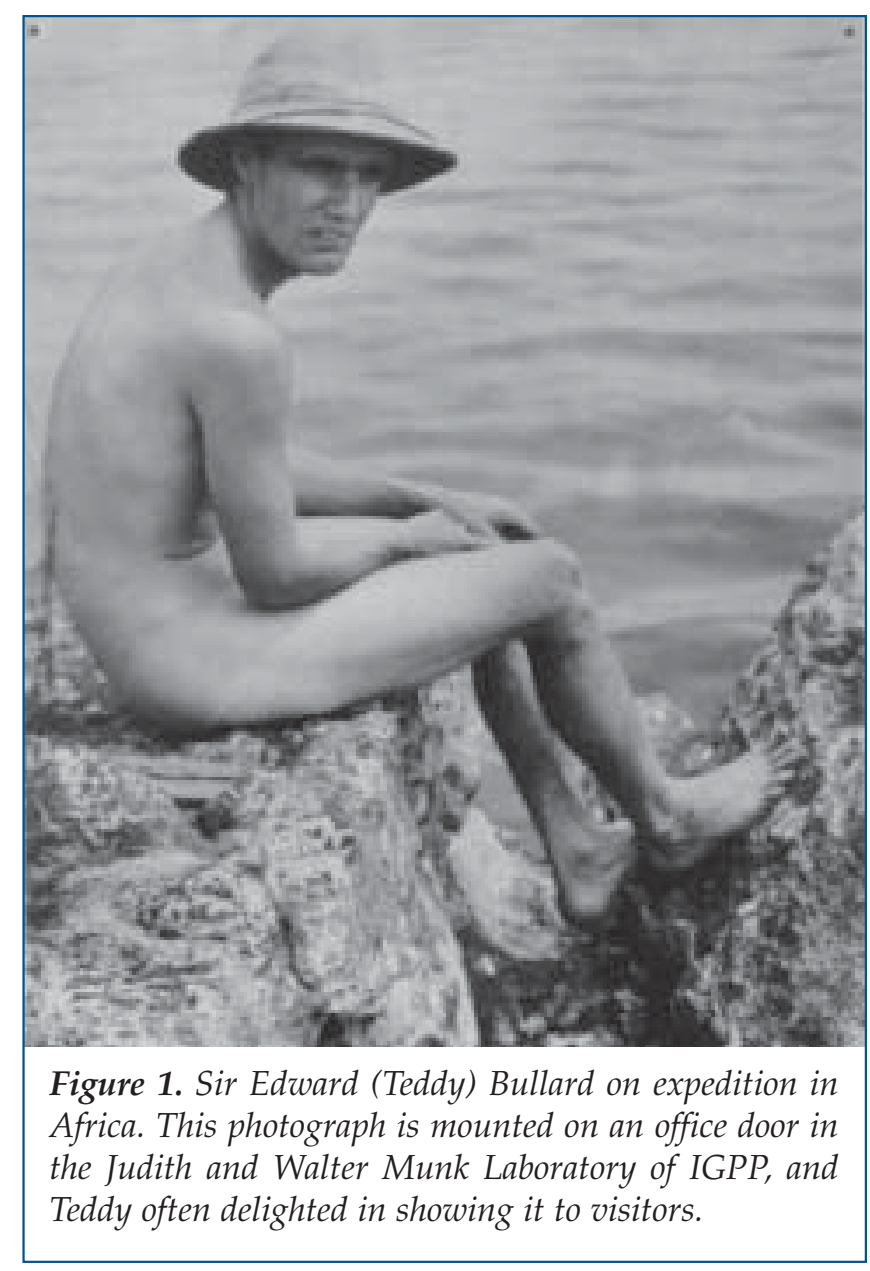

Harvard University that included a departmental leadership role and provided an easier platform for integrative geophysics than could be found at Scripps at that time. Scripps Director Roger Revelle asked, "Is there anything that you could do there that you could not do at Scripps?"

I held an absentee appointment at IGP/UCLA (not yet IGPP), which led, naturally, to the idea of a La Jolla branch of the institute. On April 23, 1959, we received a UCLA grant of $\$ 1,000$ in petty cash and $\$ 2,500$ for research assistants for "minor but immediate support," and IGP/LJ was under way!

The formation of a geophysical center at Scripps was a natural step in the progression from a marine biological station under founding director William E. Ritter and his successor T. Wayland Vaughan, to an oceanographic institution under Harald U. Sverdrup, to a center for serious geological/geophysical explorations under Roger (and eventually to an inevitable expansion into climate and atmospheric research). Initially, we held weekly seminars alternately in Los
Angeles and La Jolla. A serious conflict developed between the statewide director, Louis Slichter, at UCLA and the Scripps director, Roger, with regard to primary responsibility for the La Jolla branch. This was eventually resolved in favor of local control, and marked the beginning of a decentralized IGPP/LJ with activities on many campuses.

For those of us in La Jolla, the question of institutional size was a major consideration from the very beginning (as it is today). Wartime activities had led to an explosive growth of Scripps efforts, and although Roger was not afraid of "big science," most of the rest of us were. In 1959 I wrote the following:

The informal intimacy of the early days is now gone; we have professional administrators and parking problems. I have found these developments very disturbing, yet have become convinced that a modern scientific institution must have a broader base than that of the Scripps Institution during Sverdrup's days. Is it possible to combine the advantages of a small, intimate institute with the advantages provided by a modern well-rounded campus? Could one establish an institute sufficiently small so that its director can devote most of his time to teaching and research, and sufficiently remote to provide peaceful intimacy among its members?

It is interesting that this was written when Scripps was about the size that IGPP/LJ is today. (I lost all credibility as an advocate of intimate scholarship when, in the 1990s, I started the \$35 million Acoustic Thermometry of Ocean Climate [ATOC] program.)

Finding a "sufficiently remote" site was a major consideration. ${ }^{3}$ We chose the site of the old Scripps Community House where, in 1939, I spent my first summer at Scripps. University authorities raised a host of objections: the site was too remote from other Scripps activities (it is now in the center of the campus); Lloyd Ruocco (our choice for architect) had never built a laboratory; it was not possible to build a laboratory out of redwood because it wouldn't last; it was too close to the cliff. To make the last point, UC retained a soil specialist (at our expense) who took the UC view, using for support a paper on cliff erosion by Scripps Professor Francis Shepard. Fortunately, I ran into Francis the morning of the review and he told me that he had changed his mind. When the consultant recommended that "the building should be moved as far away from the cliff as was consistent with other considerations," I could reply that it was.

Initial plans provided for 50,000 square feet of laboratory and office space. ${ }^{4} \mathrm{UC}$ agreed to pay half of the estimated cost of $\$ 972,000$ if we could come up with the rest of the money. We were working on a project

${ }^{3}$ With Judith Munk's lead, we have always taken architectural problems very seriously. During the construction of the Revelle Laboratory in the 1990s, John and Sharyn Orcutt, Judith and Walter Munk, and Christina Seabern watched every step of the design and construction. It showed! By that time we had won the support of Chancellor Atkinson, who admired the early laboratory.

${ }^{4}$ Not counting mezzanine and basement space, which were inserted surreptitiously. 


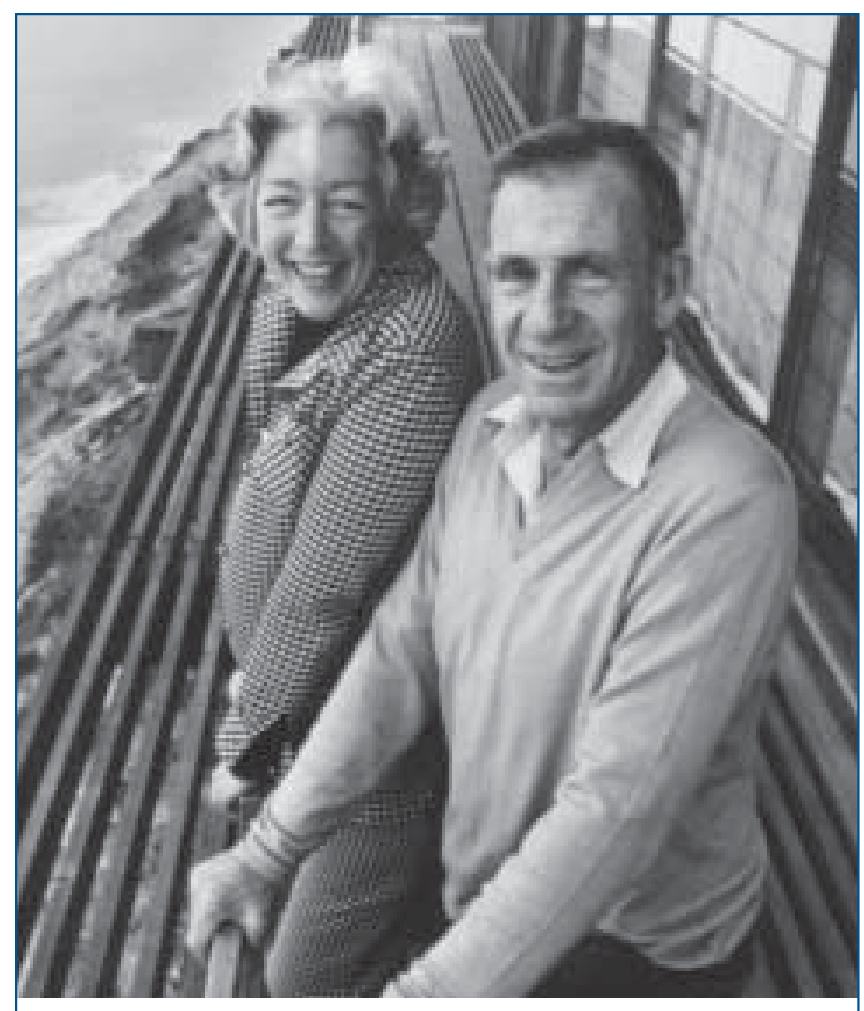

Figure 2. Judith and Walter Munk overlooking the Pacific Ocean on the deck of the newly completed IGPP building at Scripps in 1963. In 1993 the building was officially named the Judith and Walter Munk Laboratory.

(called Vela Uniform) using seismometers to monitor the nuclear test ban (as we still do). In 1959, the commander of the U.S. Air Force Office of Scientific Research came to review our work and learned of plans for the laboratory. He asked what he could do to help and I replied, "Give us \$486,000." He offered $\$ 243,000$ provided we could find the other half. The National Science Foundation (NSF) subsequently offered $\$ 121,500$, provided we could raise the remainder, and the Fleischmann Foundation offered \$60,750. This process had all the earmarks of a geometric series $-\Sigma 2^{-n}=1$-provided the upper limit is infinity. We were down to just $\$ 30,000$ left to raise when the U.S. Steel Foundation closed the gap.

We made a special effort to control noise levels, and used carpets everywhere (called "acoustic floor covering" to circumvent a UC rule that only the president's office was entitled to carpet). We avoided unsightly movable partitions (then in vogue) in favor of two-by-fours that could be knocked out to make interior modifications. We pioneered portable laboratories in containers that could be trucked to the research vessel and secured to the deck. These portable laboratories were outfitted and calibrated as extensions to permanent laboratories prior to going into the field. The permanent laboratories were divided into an inner electronic space and an outer "wet" space on a ratio of

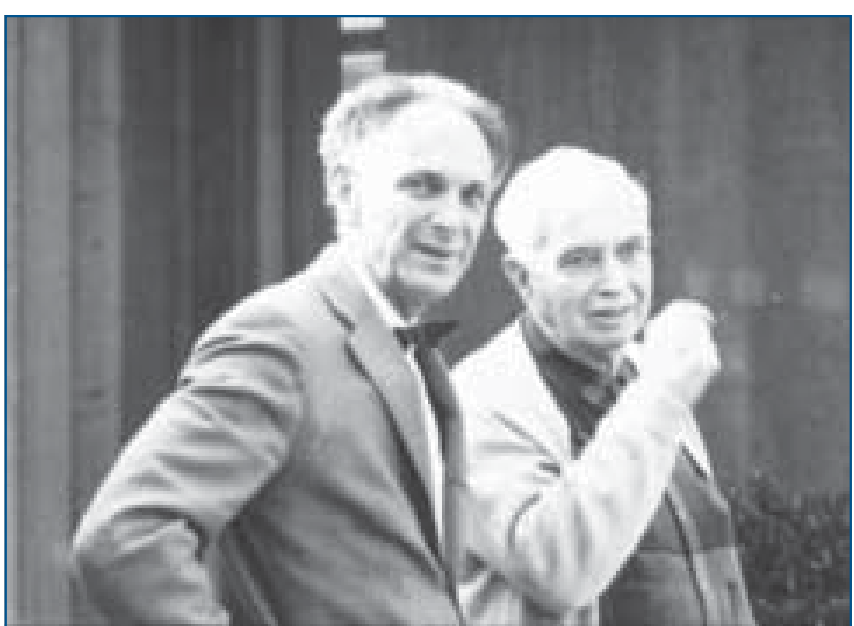

Figure 3. IGPP's architect Lloyd Ruocco (left) and sculptor Donal Hord at the installation of Hord's diorite sculpture Spring Stirring at IGPP in 1964.

1:2. The major change over the last 40 years has been to move the partition so that this ratio is now 2:1, to accommodate evolving technology.

The laboratory was completed in November 1963 - on time and at cost. It cost $\$ 20.86$ per assignable square foot (at the same time, Jonas Salk was building his laboratory to the north of us for $\$ 120$ per asf). Famed architect I. M. Pei had just completed the Green Geophysical Laboratory at MIT when Cecil Green came to visit us. After a tour, he opined that ours was the more livable structure (it is) and insisted to give us a move-in present. Judith Munk said at once, "Give us Spring Stirring," a diorite sculpture by Donal Hord (Figures 2, 3). Ever since, Spring Stirring has been sitting outside the seminar room as our guardian angel.

But our true guardian angels were not made of diorite. Two men, Cecil Green and Teddy Bullard, made IGPP what it is today. In 1971, Cecil took the initiative to suggest that IGPP was below minimum mass and that it should have an active program of exchange with the outside geophysical world. He offered to establish an endowment of $\$ 600,000$ providing an income to support visiting scholars (with a tenure between two months-to avoid tourist-oriented visitsand two years - to avoid any excuse by UC for not following up with some promised permanent appointments). In choosing Green Scholars, we alternate between famous men and women and promising postdocs. We have just welcomed the 120th Scholar, and the list of Green Scholars is a veritable "Who's Who" in the geophysical sciences. Cecil's intimate involvement with IGPP did not stop there; he helped us acquire a section of land at Piñon Flat to conduct measurements of Earth's strain and to establish Project IDA's global network of digital low-frequency seismometers. 
Teddy's involvement centered on his personal standing in the geophysical community. He played a significant role in adapting four basic geophysical techniques to shipboard use: seismology, gravity, magnetics, and heat flow. Prior to World War II, these adaptations had been considered too difficult for deployment at sea, but eventually, the application of the four techniques proved more successful at sea than on land. We were incredibly fortunate that the early development of IGPP coincided with the development of the theory of plate dynamics. Here again, the Bullard Laboratory played a leading role, and the intimate exchange between the La Jolla and Cambridge laboratories helped put IGPP/LJ on the map. There are few among us who have not spent time at both laboratories (current IGPP Director Robert Parker was a Bullard student). In his later years Teddy also spent winters with us in La Jolla.

As always, the most important decisions revolved around faculty appointments. George Backus and Freeman Gilbert (both with prior connections with Cecil Green) combined pioneering work on Inverse Theory with the development of gravimeters capable of resolving Earth's normal modes. The development of the laser strain meter at Piñon Flat facilitated earth strain monitoring in real time, rather than inferring it from fossil evidence.

In continuation of the war effort on wave prediction for amphibious landings, Frank Snodgrass and I devoted our attention for two decades to ocean waves of increasingly lower frequency. We demonstrated that the long California summer swell is generated by the winter storms in the Southern Hemisphere, some from antipodal distances in the Indian Ocean. (This is now well known by the large surfing community, but was then considered wildly speculative.) We went on to "surf-beats" and edge waves, curiosities that became part of the lexicon of coastal processes, and then on to internal waves and tides, leading to the "Response Method" of tide prediction. Snodgrass developed the autonomous deep-sea tide capsules that were dropped freely to the seafloor and recalled months later by acoustic command. These technologies facilitated a natural transition to John Orcutt's ocean-bottom seismometry. All of this is now routine, but it was anything but routine in the 1960s.

IGPP was equally divided between fluid and solid geophysics, and Backus' famous course on continuum mechanics served both student groups. I regret that this symbiosis has now given way to separate and remote groups.

Research funding was not a significant problem. Program officers at the Office of Naval Research (ONR) were familiar with proposed and ongoing work and could support worthy projects without lengthy peer reviews. I once received a sum in excess of what had been requested in my research proposal. When I called for clarification, the answer was, "We thought you could use some flexible support to help get IGPP started."

\section{Freeman Gilbert Writes}

My first office at Scripps was in Sverdrup Hall (1961), next to that of Vic Vacquier. It was very conveniently located, just a few steps to the parking lot and even closer to the computer center. Keith Brueckner had succeeded with a proposal to the Atomic Energy Commission for the first general-purpose computer at UCLJ (LJ for La Jolla; though the university's name was changed to UCSD a few years later). The machine was a Control Data Corporation (CDC) 1604, designed by Seymour Cray. It was revolutionary at the time, with electronics based on transistors rather than vacuum tubes. In late 1963, the new IGPP building, now the Judith and Walter Munk Laboratory, was finished and I moved my office to that location. The computer center was relocated to Urey Hall at the general campus on the mesa, and the false floor from the machine room in Sverdrup Hall was given to IGPP and installed in the basement. It remained there for nearly 25 years, supporting a sequence of computer equipment that included (a) a CDC 160-A, with a remote link to the center in Urey Hall at UCSD; (b) a clandestine, but eminently useful link to Lawrence Berkeley National Laboratory and its CDC 7600, and (c) the Prime 750 facility, a Scripps-wide minicomputer system. With the advent of personal computers in the early 1980s and workstations in the late 1980s, the minicomputer followed the central computer center into history. However, Scripps in general and IGPP in particular were strong supporters of the establishment of the San Diego Supercomputer Center and its satellites in 1985. Computational geophysics has always been a strong facet of IGPP.

Instrument development at IGPP has had some notable successes. In the early 1960s, most scientific instruments provided analog output, often recorded on charts by pen and ink. Only a few instruments had digital output that could be recorded on magnetic tape. Richard Haubrich and H. Iyer developed what I recall as the world's first digital seismograph at IGPP in 1961. The improvement in dynamic range and fidelity over analog recording was a boon to analysts. Two years later, Hugh Bradner developed the first successful ocean-bottom seismograph (OBS) that could be deployed and recalled with reasonable success. The technology was derived from the Snodgrass-Munk deep-sea tide capsules. By 1968, Ralph Lovberg and Jon Berger had developed the first functional Laser Strain Meter (LSM) for measuring strain in the earth. 


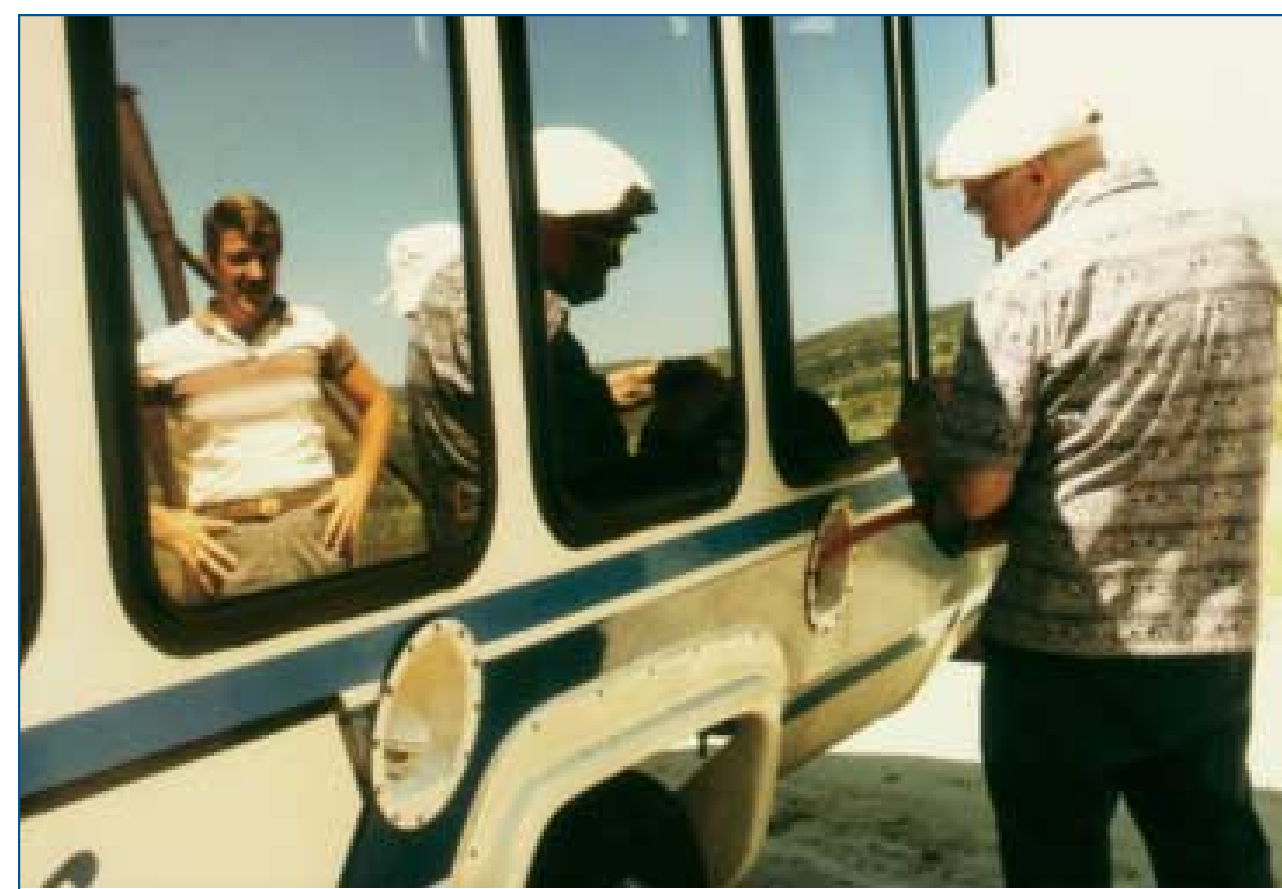

Figure 4. John Orcutt reflected in the minibus window while Cecil Green fills the empty tank. The bus had unexpectedly run out of gas on the way to the annual picnic at Piñon Flat Observatory in 1984.

about five research centers. Two postdocs from Cambridge University, Dan McKenzie and Robert Parker worked at IGPP during the summer of 1967 on their concepts. In December of that year, they published in Nature their paper, "The North Pacific: An Example of Tectonics on a Sphere." Instant fame followed. They had scooped the competition by months. No doubt, the unique facilities at IGPP had accelerated their success. Moreover, the institutional affiliation on the paper is Institute of Geophysics and Planetary Physics, University of California, San Diego.

On July 31, 1970, a very large, very deep earthquake occurred beneath Colombia. Fortunately, William Farrell was able to obtain a superb recording of the earthquake on a LaCoste \& Romberg instrument at Payson,

While the first installation was made at UCSD's Camp Elliott field station, a three-component LSM with arms some $800 \mathrm{~m}$ in length was subsequently installed at the IGPP-run Piñon Flat Observatory. The San Fernando earthquake (February 9, 1971) was well recorded by the first LSM; for the first time, the LSM unambiguously recorded a strain step for that earthquake (Figure 4).

One of the problems with a seismograph (accelerometer) is that the response of its moving mass is weakly nonlinear. The solution to this problem is to keep the sensing mass from moving by using a negative feedback system. Robert Moore and William Farrell developed the first electrostatically fedback accelerometer in 1969. The instrument they modified was an old version of the LaCoste \& Romberg gravity meter, considered to be obsolete, but it was soon to play a major role in the ensuing decade.

During the 1960s, two major conceptual changes in geophysics arose at IGPP. These have come to be known as Inverse Theory and Plate Tectonics. The first, Inverse Theory (and practice, too), is concerned with finding models that fit a given set of data (including constraints and prejudices) and, just as important, with determining what features of a model are resolved by the data (and the constraints and prejudices). This latter point is frequently ignored. George Backus and I authored the first papers on Inverse Theory (Robert Parker, subsequently extended the theory). The second major conceptual change in geophysics, Plate Tectonics, erupted more or less simultaneously at
Arizona. The analysis of the recording revealed many signals previously unobserved. Those of us involved in the analysis had the same idea simultaneously. What if we had a global array of long-period accelerometers to study large (and hopefully benign) earthquakes? Thus, the concept for the International Deployment of Accelerometers (IDA) was born. With logistical support from the NSF and funds for instrumentation (the LaCoste \& Romberg sensors) provided by Cecil H. and Ida M. Green, Project IDA became a success. The early IDA team included Duncan Agnew, Jon Berger, Raymond Buland, D. Miller, William Farrell, and myself. Today, a modernized IDA network, operated by IGPP and directed by Jon Berger, is a major component of the Global Seismic Network, which is managed by the Incorporated Research Institutions for Seismology (IRIS).

In the 1970s, considerable progress was made in seismology. I introduced a phenomenological description of the earthquake (or explosion) source called the moment tensor formalism. Subsequently, George Backus and M. Mulcahy (at Princeton University) showed how to interpret low-order temporal and spatial moments of the source. Adam Dziewonski (then at the University of Texas at Dallas, now at Harvard University) and I used the formalism to analyze recordings of the great Alaska earthquake of March 28, 1964. Among other things, we were able to show that the inner core of the earth is solid. Robert Parker treated the inverse problem of electrical conductivity in the 
mantle, and George developed a filtering theory to study a rapid change in the earth's magnetic field, called a jerk, which occurred in 1969. Toward the end of the decade, the Greens helped IGPP obtain land for the Piñon Flat Observatory where Duncan Agnew, Jon Berger, R. Lovberg, and Frank Wyatt had constructed the three-component LSM.

The LSM requires very stable anchors for its two ends. Real earth materials near the surface respond to rainfall, expanding or contracting with wet or dry conditions. Thus, on occasion, the LSM can be more of a rain gauge than an earth strain meter. This problem can be remedied by constructing deep anchors and monitoring their movement relative to the ends of LSM. Frank Wyatt, K. Beckstrom, and Jon Berger developed the laser optical anchor for this purpose. The anchor consists of two slanted boreholes with reflectors at the bottom of each for the probing laser beam. This technology is quite successful and has replaced more traditional surveying monuments. Today, it is known as the Wyatt Anchor.

A major improvement in methods of spectrum analysis was published in 1982 by David Thomson (Bell Labs). During the summer of 1983, he was a Green Scholar at IGPP and presented a series of lectures about the new method, called multitaper spectrum analysis. Graduate students Craig Lindberg and Jeffrey Park and researcher Frank Vernon quickly adapted the multipaper method for several applications in seismology, and researcher Alan Chave extended the method to geomagnetic data. The generality of the method, useful for both time series and uniformly sampled space series, makes it universally appealing. Other achievements in the 1980s included my discovery with Guy Masters of anomalous splitting of earth modes sensitive to the inner core (now explained by anisotropy of the inner core) and the discovery of a large aspherical structure in the mid-mantle. The paper in Nature was authored by Guy Masters, Tom Jordan, Paul Silver, and me. Parker continued his investigations of Inverse Theory for several electrical and electromagnetic inverse problems.

During the 1970s and 1980s, members of IGPP made important contributions to the understanding of geomagnetism and electromagnetic induction studies. By this time, George Backus had already provided a number of powerful theoretical insights into geomagnetism, including proof that a viable self-sustaining geodynamo might exist in the core. These works, together with the development of Inverse Theory at IGPP and its subsequent evolution, have had the most far-reaching effects on the whole subject of geomagnetism. In 1983, Lisa Tauxe established a paleomagnetic lab in Scripps's Geosciences Research Division at about the same time Cathy Constable arrived as a graduate student at IGPP. The emphasis at IGPP was on theoretical developments, but these became firmly grounded in reality by the influence of practicing paleomag- netists. Fertile collaborations between Constable, Parker, and Tauxe have led to the adaptation of many of the standard techniques used in modern geomagnetic field modeling for use with global paleomagnetic datasets.

In 1964, John Miles joined the IGPP/LJ faculty from UCLA, where he had been professor of engineering since 1945 (two years of which he spent at Australian National University). A virtuoso at applied mathematics, John has published more than 400 papers on every aspect of fluid mechanics, and has served as editor of the prestigious Journal of Fluid Mechanics for 34 years. He is especially known for his work on all types of waves; his 1957 theory of ocean surface wave generation by wind is still one of the most widely cited papers in the field. He left IGPP temporarily, from 1980 to 1983 , to assume the position of vice chancellor for academic affairs at UCSD.

Dave Sandwell joined the faculty of IGPP in 1989. Using the satellite derived height of the global sea surface, he computed a new map of the seafloor based on its gravitational effect on the shape of the sea surface. Previously unmapped features of seafloor geomorphology, particularly in the Southern Ocean, helped to complete the picture of plate tectonics. "Smith and Sandwell topography" (referring to the collaboration between Walter Smith of the National Oceanic and Atmospheric Administration [NOAA] and Dave Sandwell) has become a standard reference in marine geophysics. Later, Dave applied his mapping expertise to the analysis of radar images on land, contributing significantly to the burgeoning field of interferometric synthetic aperture radar (InSAR).

IGPP is a multifaceted research unit where instrumentation, observation, theory, and computation are symplectically combined in a way that has led to success in geophysical research.

\section{John Orcutt Writes}

The systemwide director of IGPP typically resided at the UCLA branch until 1994 when Bernard Minster became the systemwide director in La Jolla. Bernard has been an energetic director, overseeing a quinquennial review of IGPP (in spite of the name normally conducted about once a decade by the UC Office of the President). He initiated new branches of IGPP at UCSC and UCB although the UCB branch has never become an active participant largely because of budget disagreements with the UC Office of the President. While pursuing major new programs in satellite observations of the cryosphere and lithosphere (laser altimetry and synthetic aperture radar), Bernard has had to spend an increasing amount of his time dealing with the deteriorating relationships between the U.S. Department of Energy and UC over management and security issues. IGPP has branches at the Los Alamos and Lawrence Livermore National Laboratories, which are particular- 


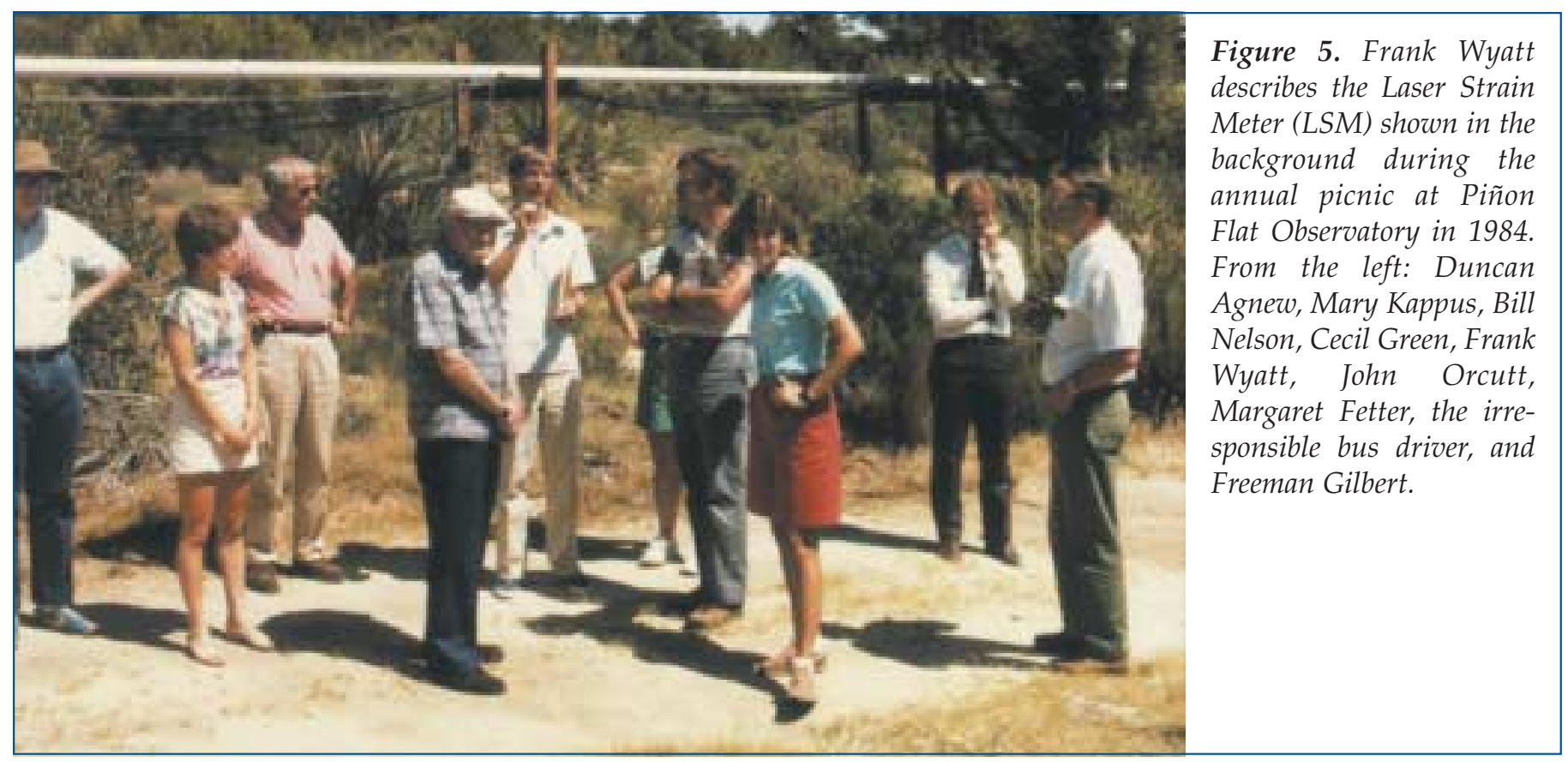

ly vulnerable to loss of revenues. The next chapter on this very public dispute, and its inevitable impact on systemwide IGPP, will be written well after this paper is published.

My term as director of IGPP began in 1984 (when Freeman Gilbert asked me to work with him as codirector) and lasted for an extraordinarily pleasant 19 years. Freeman left me with the full job in 1988 when he became chairman of the Scripps Graduate Department, but I was always deeply grateful for the tutelage he provided during those years when we worked so closely together. The director's job at IGPP is such a puny title within the great UC bureaucracy that no one seems to have noticed that there have only been five directors in its 44-year history of IGPP/LJ (Figure 5).

Computational geophysics has always been important to directions IGPP has taken and more will be said of this in the discussion of instrument development. Freeman Gilbert worked to ensure that leadingedge computational resources were always available. He enlisted help in the mid-1970s when the first minicomputer at UCSD was installed at IGPP. The Scripps director at the time, William A. Nierenberg, fought a remarkably bloody battle with the chancellor and campus central computing facility over the introduction of this alien architecture. Gilbert was also instrumental in bringing the San Diego Supercomputer Center (SDSC) to the UCSD campus in 1985. During the period when I was IGPP director, I continued to emphasize the importance of what is now generally called "information technology."

The ARPANET experiment in the 1970s had been very successful in introducing the Internet to the scientific community, and even simple tools like e-mail and file transfers had a major impact on collaborative scientific research. IGPP developed its own (now 4.5 fulltime employees) network operations group supported almost entirely by extramural grants. This practice continues today and the fact that this procedure was not adopted elsewhere at Scripps speaks to the special academic environment at IGPP. During the past 20 years, we have managed to always maintain the highest speed networks at UCSD, aided substantially by SDSC's function as a network hub. The installation of a modern visualization center at IGPP, the only example of such a state-of-the-art facility in a geosciences department, recently bumped network speeds to OC192/10 Gbps. Even more recently, fiber optics and routers were installed to support network speeds in excess of $40 \mathrm{Gbps}$ to support computational and visualization projects on the NSF-funded OptIPuter (Optical IP computer). With assistance from the California Institute for Telecommunications and Information Technology (Cal-(IT)2), we plan to exploit the intellectual and engineering opportunities (and turmoil) associated with (a) network bandwidth doubling times of less than a year compared with (b) the substantially slower processor density doubling time of 18 months (Moore's Law) as we make new forms of computation in the geosciences possible.

The development of new instrumentation for oceanography is critical. A recent report of the National Science Board observed the following:

Instrumentation research is often difficult and risky, requiring the successful integration of theoretical knowledge, engineering and software design, and information technology. In contrast to most other infrastructure technologies, commercially 
available data analysis and data interpretation software typically lags well behind university developed software, which is often not funded or underfunded, limiting its use and accessibility. This research will accelerate the development of instrument technology to ensure that future research instruments and tools are as efficient and effective as possible.

New discoveries in the earth sciences in general, and oceanography in particular, have nearly always followed the development of a new instrument capable of measuring a new variable or measuring with significantly enhanced fidelity. The bulk of the new instrumentation has been researched and developed by the oceanographic community, and the modern commercialization of sensors relies increasingly upon partnerships between academic laboratories and small companies that manufacture instruments. The development of the ocean-bottom seismograph at IGPP was important for me, although this happened years before I arrived.

When I came to IGPP as a student (1973), Bill Prothero had already built the first digital seafloor seismograph (the first digital seismograph intended for land use was built at IGPP in 1961). Prothero had also built the first digital, fedback, broadband, ocean-bottom seismograph comprising an IGPP Block-Moore quartz accelerometer with an internal coaxial seven-track tape drive. Moore's Law (the other Moore), mentioned earlier, took over and many generations of instruments followed. Early in the process, the reliability of discrete logic circuits was very low and data return, as well as instrument return, statistics were poor. The original resolution of digital instruments was also very low (eight bits). This increased to 12 bits, 16 bits, and finally 24 bits. The first use of 24-bit encoding for seismology was done at IGPP on a seafloor borehole seismometer funded by the Defense Advanced Research Projects Agency for the follow-on to project Vela Uniform. Today, IGPP operates the most successful seafloor instruments in the world (80 altogether) with instrument return rates of 99 percent and data return rates of 98 percent, unparalleled by any other autonomous field instrumentation in academia. Continuing and accelerating turnover in instrumentation has been critical to this success-not at all unlike computing infrastructure.

My younger colleagues (Graham Kent, Alistair Harding, and Jeff Babcock) and I have used these instruments to make the first detection of a magma chamber under midocean ridges and to map the threedimensional structure of the ridge. The latest achievement has been the use by Gabi Laske of simple pressure instruments to record surface waves for period in excess of a year in a pilot experiment to map the mantle plume beneath the Hawaiian Hot Spot. Steve Constable developed a variant of the seismic instruments for making high-fidelity magnetotelluric measurements at the seafloor for studying electrical properties of the crust and mantle. In 1996, he used the instruments for the first time to study oil and gas distribution within the continental margins, a technique that has become extremely useful and popular within the oil exploration industry. The instrumentation for making seafloor seismic measurements, developed and vastly improved over more than 40 years at IGPP, is certain to engender a period of unprecedented scientific opportunity.

Mark Zumberge developed the first easily portable absolute gravity meter as a Ph.D. student at the University of Colorado. Later at IGPP, he made the first measurement of absolute gravity on the seafloor in 1994. Later, he continued with the development of relative gravimeters of high resolution and precision, making measurements on and above the seafloor. These instruments are becoming important tools for studies of midocean ridges and the evolution of petroleum reservoirs as hydrocarbons are extracted. Even earlier, Mark had used his facilities for development of complex oceanographic instruments with Bob Parker to explore the possible scale dependence of the universal gravitational constant, G. In 1991, he used the Sea Cliff manned submersible to make gravity measurements through a five-km column of seawater near Hawaii to show convincingly that there was not a detectable scale dependence and to add another decimal point to the value of $G$.

Mark's experiments with fiber optics and interferometry have led to measurements of ice deformation near ice rivers in the West Antarctic Ice Sheet and to the development, with Jon Berger, of a fiber-optical infrasound sensor remarkably quieter than earlier instruments based on refinements of microphone technology. With Green Scholar Erhard Wielandt, Mark, and Jon have begun the promising development of a new seismometer technology that replaces electronics with optics and eliminates the need for a 24-bit data logger. The result will be a simpler seismometer with potentially greater resolution than the best instruments available commercially today.

In the mid-1990s, the value of satellite altimetry in mapping the seafloor became very clear. Professor Dave Sandwell developed a technique for using highwave number components of the height of the ocean to infer the topography of the seafloor because of the relationship between gravitational attraction of seafloor 
features and the height of the overlying water column. He worked with me in persuading the U.S. Navy to relinquish classified altimetry data from the GEOSAT satellite mission for research use. This declassification, of course, was greatly aided by the flight of the French ERS-1 satellite, which produced data of essentially equal quality. With Walter Smith, formerly a postdoc at IGPP and now a scientist at NOAA, Dave produced the first uniform map of the seafloor using the altimetry data coupled with available ship soundings from NOAA's National Geophysical Data Center in Colorado. The map has become quite well known and is used today for an increasing number of studies of the genesis and evolution of the seafloor. He has shown how NASA could readily and inexpensively enhance the quality of data by a factor of three or four with a new, relatively inexpensive, radar mission on the space station.

One of the most masterful applications of technology to geophysics during the past 15 years, involving an entirely new tool, has been the introduction of acoustic thermometry for measuring the average temperature profile of ocean basins. The idea is simple: a higher temperature increases ocean sound velocity, which in turn shortens the travel time between fixed sources and receivers. A secular change could be detected buried in the noise of interannual variability over the course of some years to determine if anthropogenic additions of greenhouse gases were increasing ocean temperatures. Walter Munk and Peter Worcester first applied the idea in the Heard Island experiment in 1991 with resounding success. They showed the method was so well behaved that that they could track a ship's motion nearly at the antipode using the Doppler shift in the transmitted sound with an accuracy equal to that of the global positioning system (GPS) - a model for the ocean equivalent of GPS. After this promising start on understanding the climate system, progress was slowed enormously by complaints from environmentalists that the sound levels in use could harm marine mammals. Pete's remarkable patience in working through overlapping legal jurisdictions and language and in conducting lengthy and expensive experiments on potential effects on marine mammals (with negative results) have allowed acoustic thermometry to continue in the North Pacific Basin as well as in more regional experiments around the world.

The advent of the availability of the GPS has had a tremendous impact on the field of geodesy. Yehuda Bock and Duncan Agnew experimented with the use of GPS for making point measurements of geodetic accuracy in the 1980s. In 1990, Yehuda established the first permanent array of GPS stations in the United States and dubbed it the Permanent GPS Geodetic Array (PGGA). The program grew substantially and was combined in 1996 with a larger program involving other institutions (Southern California Integrated GPS
Network [SCIGN]). Today more than 250 stations are operating in southern California, many of them telemetering data in real time and with sample rates as high as one Hz. The secular behavior of strain in southern California is much better understood today, facilitating earthquake forecasting and the reliable mapping of earthquake hazards.

During the past several years Frank Vernon and I, working closely with SDSC and Cal-(IT) ${ }^{2}$, have extended the Internet from the laboratory to the field. A scientific wireless network now extends throughout southern California and onto the high seas (Jon Berger). New middleware extends measurements from sensors with Internet Protocol (IP) addresses and duplex communications to scientists in real time. A Virtual Seismic Network allows users anywhere in the world to have access to more than 1,100 seismic stations with latencies of seconds.

While technology will not advance significantly through a relationship with geophysics, geophysics depends critically upon the continual introduction of new technologies.

\section{Mark Zumberge Writes}

I have been the deputy director of the La Jolla branch of IGPP for the past decade. Presently, while Bob Parker is on sabbatical, I am the acting director (for a while, I was actually the "acting acting director"). I leave the coverage of science at IGPP to the other coauthors except to note how gratifying it is to work in an environment where theorists not only appreciate instrument development but also gladly lend their expertise to it when asked.

I began my part-time administrative stint in the early 1990s when IGPP was undergoing a growth spurt. Project IDA was expanding and upgrading its worldwide seismic stations, ATOC was being launched, a new geodetic research group (with the advent of highly precise GPS observations) had sprouted, and ocean-bottom seismology was beginning a long, steady ramp-up that continues today. We needed more space.

For some time the IGPP directors had bandied about the addition of a second IGPP laboratory, but nothing materialized until Walter and Judith Munk made a gift to Scripps specifically earmarked for this purpose, immediately matched by the Revelles and more than matched by the Greens. These private gifts opened the door for seeking public funds under the Garamendi Program, which permitted the application of overhead from federal research grants to the construction of required research space. The ongoing expansion of various IGPP research programs made the case.

The precedent set by the original redwood IGPP building set the bar high for any architect willing to take on the challenge of designing an addition. Walter 


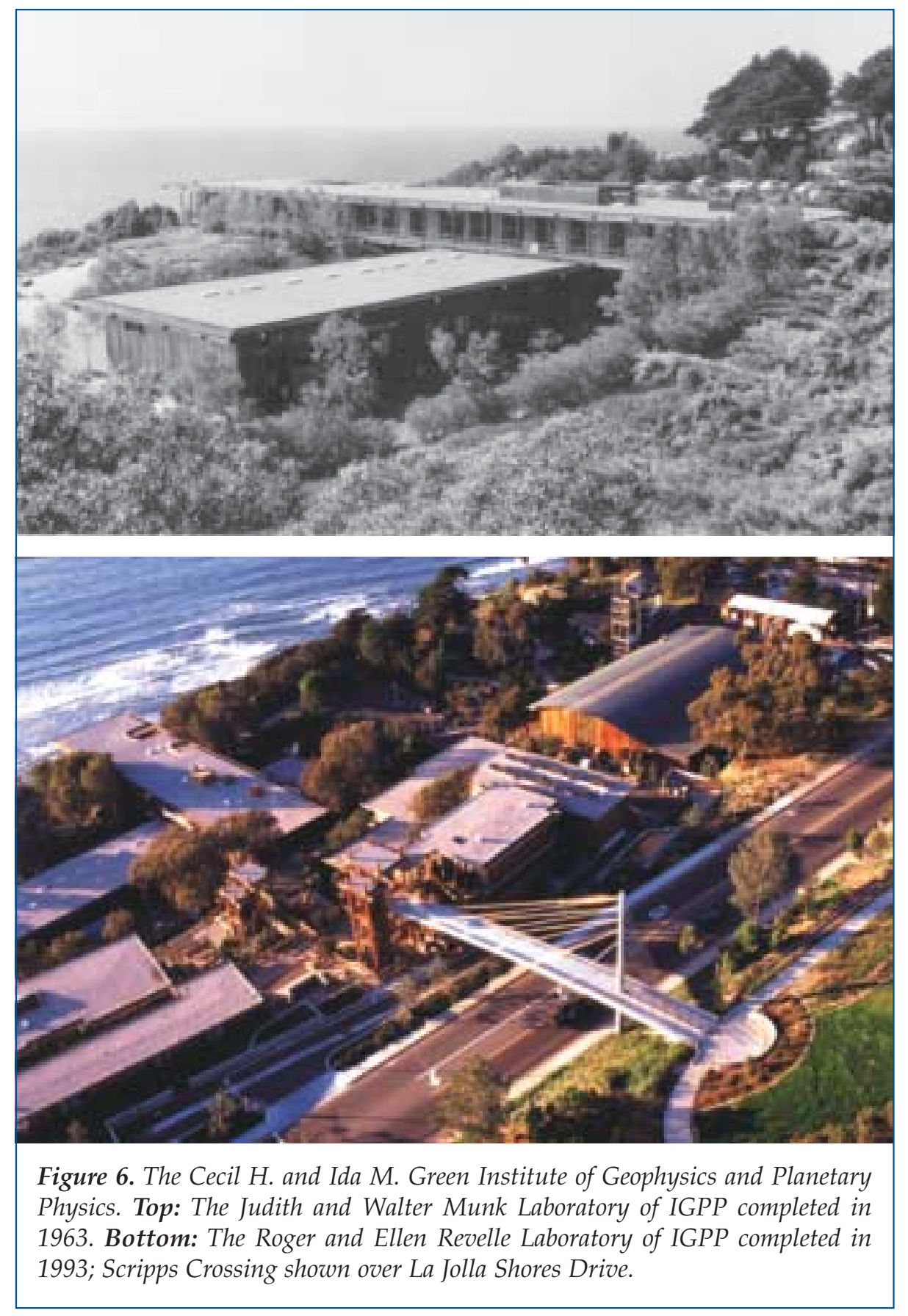

to be satisfied with the design, the decision to construct another wooden building (an oddity in a modern campus setting) was made a nonnegotiable fait accompli by using private funds to purchase the redwood in advance of final university approval.

During construction, the authors of this article participated in weekly inspections of the construction site. The general contractor soon learned that his clients were not detached bureaucrats from the university administration; rather they were the future denizens of the building-and demanding ones at that. The resulting attention to detail won architectural awards and public acclaim.

The Scripps campus consists of the older section adjacent to the ocean and a rapidly growing inland section. The two halves of the campus are sharply separated in elevation and by a high-speed public road. An auxiliary goal for the new laboratory was to provide a cross-campus connection that was convenient, safe, and attractive; private funds were earmarked accordingly. The connection is accomplished by seven stories of scenic elevator access, and, for the hardy, a broad stairway called "Scripps Ladder," and a cable-stayed bridge (the first in western America) designed by UCSD engineer Frieder Seible, now the dean of the Jacobs School of Engineering. The bridge has become a La Jolla landmark (Figure 6).
Munk and John Orcutt, along with their wives, Judith Munk and Sharyn Orcutt, began a series of meetings with architect Fred Liebhardt. Judith Munk, who studied art and architecture for many years, proved to be an especially insightful contributor to the discussions. Not long after, a committee was formed to work with the architect's original concepts to bring about a design that was both functional for research and as attractive as its predecessor. The building site, a steep hillside above the original building, required the new addition to be made up of four small, separate structures. Redwood was selected for both the exterior and the interior, as was the case with the first IGPP building. While many campus authorities and committees had

\section{Robert Parker Writes}

As the very new, current director it falls upon me to address the future of IGPP and, perhaps, to imagine it fulfilling my own aspirations. In 1976, in an address I gave to American Geophysical Union members, I said that the IGPP of the time was a "geophysical paradise." In developing my thoughts on the future, I intend to look back to that time for clues as to what constitutes for me such a heavenly garden of science. My own modest talents tend toward a mathematical and theoretical direction, and the early IGPP had a perfect combination of people working on theoretical problems with abstract mathematics and observationalists testing those ideas. Freeman Gilbert and George Backus 
put the development of geophysical Inverse Theory on the firm foundation of functional analysis, but equally important was the very concrete application to normal mode seismology. Barry Block, Bob Moore, and Bill Farrell developed low-frequency seismographs capable of detecting the ringing of the earth after large earthquakes. All of this was geophysics of a completely new kind not done at the other celebrated centers in America: to the geophysicist of the day, Inverse Theory was indistinguishable from least-squares fitting (as it remains to many today) and all respectable seismometers cut off anything with a period above 20 seconds because everyone knew there was just noise down there.

The tradition was to teach all of our students advanced mathematics so that they would know the foundations for continuum mechanics, signal processing, and inverse theory without watering down the subjects for mere earth scientists. My hero was, and still is, George Backus, most of whose classes I was able to attend. He would devote himself exclusively to teaching his courses, starting each time from scratch, developing the subject from the beginning, often inventing a completely new notation. He sometimes handed out a hundred pages of handwritten notes, notes that seemed never to contain a crossing out, let alone an actual error. Each course he taught was different, though tensors would usually be worked in somehow. He would veer off into some mathematical byway; I recall him setting forth measure theory for groups, and discussing the Funk-Hecke Theorem, using, as an example, the properties of a strange captive beast called the "tethered vector bipod." The students flourished on this rich diet, although it may have been difficult to digest at the time.

Today, much of the curriculum is at or below a senior undergraduate level in physics. The students seem to struggle with math more advanced than calculus, some complain that linear algebra is too abstract, and most have no concept of a mathematical proof. A majority of the students have bachelor's degrees in earth sciences, not physics, and seem to have missed a lot of basic material (or perhaps grade inflation is taking its toll). Is this just the traditional whining of the older generation, that the golden age of students is past, yet another example of former Director Nierenberg's complaint that students these days go home to bed each night instead of sleeping under the cyclotron magnet, as they did when he was in graduate school? I don't think so. I believe that applied math and mathematical geophysics have almost completely disappeared as interests among the student body. I am not talking about computer modeling but the use of analysis to solve geophysical problems.

Another contrast with today is the fact that a quar- ter century ago funding was easy to obtain because few proposals to the Office of Naval Research or NSF were turned down. Today, competition forces our research onto well-trodden paths and toward research whose progress, though modest, is assured. Large programs, endorsed by the geophysics community, have a better chance than small-scale projects in unconventional areas. IGPP has grown, but it has to be said, we now carry out a lot more ordinary science, where a great deal of money generates only incremental advances, where new ideas are few, and radical proposals are rare indeed. It would be impolitic of me as director to be too specific.

For my part, I would like to encourage more activity in theory. This may be just a selfish concern, but IGPP's great reputation in the past was built in part on the work of giants like John Miles, George Backus, and Freeman Gilbert who are applied mathematicians as much as they are geophysicists. Theory is not a money spinner, nor can its results be easily made into a breathless press release with a discussion of how many lives might be saved or property damage prevented as a result of research. This makes theory hard to sell in the current climate at Scripps in which popularity with the public, and particularly with the wealthy, is given high priority. A recent attempt to hire a young applied mathematician for IGPP failed because of resistance from some parts of Scripps. There is no doubt that growth in this area will be difficult to achieve. Nevertheless, there are important areas in which modern mathematics has made advances relevant to geophysics: obviously, the study of nonlinear systems and chaos, although this is something of a bandwagon; the study of complex materials and how their properties emerge from their geometry; the study of partial differential equations with random coefficients; and, in particular, the propagation of signals through stochastic media, which will have so many connections to geophysics.

The future of geophysics is easy to predict: ever larger databases of seismic waveforms and crustal deformation, effortlessly available in real time; ever more elaborate codes running on ever faster and larger computers modeling the crust, the mantle, and the geomagnetic field; ever more spectacular three-dimensional, computer-generated displays to represent and interpret the data or render the results of the modeling. IGPP will be part of this future, as it must be, to compete for funding. And I hope we will be, as we are today, home to scholars for whom rigor and simplicity are also important components of their research. 